\title{
Structural and Wear Characterization of Heat Treated En24 Steel
}

\author{
Rajesh K. KHATIRKAR, Prashant YADAV and Sanjay G. SAPATE
}

Department of Metallurgical and Materials Engineering, Visvesvaraya National Institute of Technology (VNIT), South Ambazari Road, Nagpur, 440010 India._E-mail: rajesh.khatirkar@gmail.com, rajeshk@mme.vnit.ac.in, prashant_4035@yahoo.co.in, sgsapate@yahoo.com, sgsapate@mme.vnit.ac.in

(Received on February 23, 2012; accepted on March 9, 2012)

\begin{abstract}
$\mathrm{Ni}-\mathrm{Cr}-\mathrm{Mo}$ steels such as En24 steel are widely used in machine part members, gears and shafts. En24 steel is generally used in the hardened and tempered condition to achieve an optimum combination of hardness and ductility. In the present study, heat treatment response of En24 steel was investigated by variation of hardening and tempering temperature in relation to microstructure and hardness. The microstructures were studied through a combination of scanning electron microscopy (SEM) and X-ray diffraction (XRD). The hardness decreased with the increase in hardening temperature from 1123 to $1273 \mathrm{~K}$, whereas it increased slightly with the increase in hardening temperature after tempering at $823 \mathrm{~K}$. The martensitic microstructure (laths) became coarser with increase in hardening temperature. The hardness results were well supplemented by XRD results (Williamson-Hall (WH) \& modified WH plots and qualitatively by dislocation density). The specimens tempered at different temperatures (in the range 473-823 K) exhibited decreasing hardness with increase in tempering temperature. The abrasive wear tests were carried out on hardened and tempered specimens. The abrasive wear volume loss decreased with increase in tempering temperature, which was attributed to coarsening of martensite. The worn out specimens were observed under SEM, which revealed micro ploughing and cutting as important mechanisms of material removal during abrasive wear.
\end{abstract}

KEY WORDS: microstructure; hardness; dislocation density; hardening; tempering; abrasion; micro-cutting.

\section{Introduction}

$\mathrm{Ni}-\mathrm{Cr}-\mathrm{Mo}$ steels are widely used in machine part members, gears and shafts due to their high hardenability, good strength and toughness. The addition of suitable alloying elements and heat treatment is required for the development of suitable microstructures to impart a desired combination of good strength and toughness in these steels. ${ }^{1,2}$ In addition, adequate wear resistance is also required in most applications. Martensite structure is rarely used in the untempered condition due to the high internal stresses associated with the phase transformation that can cause the steels to have less ductility than needed and may also result in quench cracks, depending upon the severity of the quenching medium. ${ }^{3)}$ Martensitic transformation is associated with high dislocation density after hardening and tempering. It is well known that dislocations are created during quenching (oil/water) from the austenite region. Formation \& glide of dislocations and deformation twinning contributes to lattice invariant shear processes, which helps to accommodate the high internal stresses associated with martensitic transformation. ${ }^{3)}$ In low to medium carbon martensitic steels, the dislocations aggregate over the background of the lath structure. ${ }^{4,5)}$ Dislocations are also produced in the parent phase due to the associated martensitic shear. ${ }^{3)}$ Tempering is generally required to increase the toughness. However, there are only limited studies on the evolution of dislocation density as a function of hardening and tempering temperature in En series of steels. ${ }^{5)}$ This is partly due to difficulties in the evaluation of very high dislocation densities (typically observed in steels with martensitic microstructures) using transmission electron microscopy $(\mathrm{TEM})^{5-9)}$ and partly due to the magnetic nature of these steels.

Wear by abrasion accounts for more than $50 \%$ of the wear related failures in industries. It is not only responsible for material removal, but also leads to pre-mature failures in engineering components. ${ }^{10)}$ There have been several studies on the effect of heat treatment on microstructure and wear properties of alloy steels. ${ }^{11-17)}$ However, abrasive wear behavior of En24 steel has not been studied as a function of heat treatment variables such as hardening and tempering temperature. Similarly, no attempt has been made in the past to correlate dislocation density as a function of hardening temperature and morphology of the martensitic microstructure. In the present study the microstructural variations obtained by heat treatment were systematically investigated by Scanning Electron Microscopy (SEM) and X-ray Diffraction (XRD) analysis. The abrasive wear tests were carried out on En24 steel with different microstructures (obtained by hardening and tempering) and an attempt has been made to establish the co-relations, at least qualitatively, between abrasive wear resistance and the microstructural aspects.

\section{Experimental Work}

In the present investigation, En24 steel in the as-rolled 
and annealed condition was used to study the microstructural developments and abrasive wear behavior. The chemical composition of the En24 steel was determined by wet chemical analysis and is given in Table 1. The specimens were $25 \mathrm{~mm}$ in length with a diameter of $8 \mathrm{~mm}$. All the specimens were initially annealed at $1123 \mathrm{~K}( \pm 5 \mathrm{~K})$ for $2700 \mathrm{~s}$ followed by furnace cooling. Afterwards, first set of annealed samples (4 Nos.) was austenized at 1123, 1173,1223 and $1273 \mathrm{~K}$ for $2700 \mathrm{~s}$ respectively followed by oil quenching (oil was at $298 \mathrm{~K}$ ). The second set of annealed samples (4 Nos.) was austenized at 1123,1 173, 1223 and $1273 \mathrm{~K}$ for $2700 \mathrm{~s}$ respectively followed by oil quenching (oil was at $298 \mathrm{~K}$ ). These second set of samples were then tempered at $823 \mathrm{~K}$ for $3600 \mathrm{~s}$ followed by air cooling to room temperature $(298 \mathrm{~K})$. The third set of annealed samples (4 Nos.) was austenized at $1123 \mathrm{~K}$ followed by oil quenching (oil was at $298 \mathrm{~K}$ ) and then tempered at 473, 583, 683 and $823 \mathrm{~K}$ for $3600 \mathrm{~s}$ respectively followed by air cooling to room temperature $(298 \mathrm{~K})$. Afterwards, all the samples were subjected to detailed microstructural and XRD characterizations. All the samples were prepared, for both microstructural and X-ray measurements, by standard metallographic polishing followed by etching with $2 \%$ Nital. The bulk hardness of all the samples was measured using Rockwell hardness tester at a load of $150 \mathrm{~kg}$.

X-ray diffraction peak profiles were measured on a PANalytical's XPert Pro MPD diffractometer using $\mathrm{CuK}_{\alpha}$ radiation. The measurements were obtained using a step size of $0.02^{\circ}$ in the $2 \theta$ range $37^{\circ}$ to $120^{\circ}$ and an integration time of $30 \mathrm{~s}$ at each step. The instrument was used in the BraggBrentano configuration in line focus mode, with $0.02 \mathrm{rad}$ soller slits on both incident and diffracted side. The diffracted radiation was measured using a xenon filled point detector fitted with curved crystal graphite monochomator, which removes the fluorescent and $\mathrm{K}_{\beta}$ radiation. For the correction of instrumental broadening, a fully recrystallized silicon sample with negligible size and strain broadening was used. The X-ray data was post-processed using the software program 'Marqx'. ${ }^{18)}$ The Williamson-Hall $(\mathrm{WH})^{19)}$ and modified $\mathrm{WH}^{20,21)}$ plots were obtained by using the program 'Marqx'. WH technique ${ }^{19)}$ is a classical method to estimate qualitative information regarding size and micro-strain present in the sample. In this method, both size and strain broadening of the X-ray peak profiles are assumed to be Lorentzian and a mathematical relationship was obtained between the integral breadth $(\beta)$, volume weighted domain size $\left(D_{v}\right)$ and the micro-strain $(\mathcal{E})$ as:

$$
\frac{\beta \cos \theta}{\lambda}=\frac{1}{D_{v}}+2 \varepsilon\left(\frac{2 \sin \theta}{\lambda}\right)
$$

The plot of $\beta^{*}=\frac{\beta \cos \theta}{\lambda}$ vs. $d^{*}=\frac{2 \sin \theta}{\lambda}$ gives the values of micro-strain from the slope and domain size from the $y-$ intercept. In this technique, linear relationship is assumed and hence $\frac{\beta \cos \theta}{\lambda}$ should be a monotonous function of $\frac{2 \sin \theta}{\lambda}$. If the points are scattered, the broadening is termed fraction vector. If the strain broadening is assumed to be caused by dislocations, the integral breadths of diffraction
Table 1. Chemical composition (in weight \%) of En24 steel used in the present study.

\begin{tabular}{ccccccc}
\hline $\mathrm{C}$ & $\mathrm{Mn}$ & $\mathrm{Si}$ & $\mathrm{Cr}$ & $\mathrm{Ni}$ & $\mathrm{Mo}$ & $\mathrm{Fe}$ \\
\hline 0.40 & 0.60 & 0.30 & 1.20 & 1.50 & 0.25 & balance \\
\hline
\end{tabular}

profiles can be given by the modified $\mathrm{WH} \operatorname{plot}^{20,21)}$ as:

$$
\beta\left(d^{*}\right)=\frac{1}{D_{v}}+\alpha\left(d^{*} \bar{C}_{h k l}^{1 / 2}\right)+O\left(d^{* 2} \bar{C}_{h k l}\right)
$$

where $\alpha=\left(\frac{\pi A^{2} b^{2}}{2}\right)^{1 / 2} \rho^{1 / 2}$ is the $h k l$ independent or normalized mean square strain and $O$ indicates non-interpreted higher order terms. A is a constant which depends on the effective outer cut off radius of dislocations, $\mathrm{R}_{\mathrm{e}}, b$ is the Burger vector, $\rho$ is the dislocation density and $\bar{C}_{h k l}$ is the average contrast factor of the dislocations. ${ }^{22,23)}$ It can be seen from Eq. (2), that if dislocations are the primary source of broadening, then the integral breadth in the reciprocal space $\beta\left(d^{*}\right)$ depends on $d^{*} \sqrt{\bar{C}}$ and not on $d^{*}$. The dislocation density can be calculated from WH plot according to the method given by Williamson and Smallman: ${ }^{24}$

$$
\rho=14.4 * \varepsilon^{2} / b^{2}
$$

where $b$ is the magnitude of the Burger vector.

Microstructures of all the samples were examined using a JEOL 6380A SEM. The SEM micrographs (secondary electron and back-scatter electron) were obtained using an accelerating voltage of $20 \mathrm{kV}$. The two body abrasive wear tests were carried out using pin-on-disk machine (DUCOM make) on En24 steel specimens after hardening at $1123 \mathrm{~K}$ and tempering at different temperatures. The cylindrical specimens used for the two body abrasive wear tests were $8 \mathrm{~mm}$ in diameter and $25 \mathrm{~mm}$ in length. The specimens for abrasive wear tests were prepared by polishing up to 1000 grit emery paper followed by cleaning with ethyl alcohol. The specimen was firmly fixed in the specimen holder, while the abrasive paper (silicon carbide paper - 150 grit) was fixed on the circular steel disc, which rotates about its axis. All the tests were carried out for a period of $600 \mathrm{~s}$, giving a total sliding distance of $1131 \mathrm{~m}$. Fresh abrasive paper was used after each $120 \mathrm{~s}$ to avoid fragmentation of abrasive particles due to repeated pass of specimen over the same track. The rpm of the disc was kept constant at 300, which gives a velocity of $1.885 \mathrm{~m} / \mathrm{s}$. After the test, the specimens were cleaned with acetone and weighed on a digital electronic balance to an accuracy of $0.1 \mathrm{mg}$. The difference in initial and final weight was used to calculate the mass loss (g). In addition, abrasive wear volume loss was also calculated. The effect of load on volume loss $\left(\mathrm{mm}^{3}\right)$ of the annealed specimens of En24 steel was studied at a constant velocity of $1.885 \mathrm{~m} / \mathrm{s}$. To study the effect of microstructure on abrasive wear loss, the tests were conducted at a load of $3 \mathrm{~kg}$ and at a velocity of $1.885 \mathrm{~m} / \mathrm{s}$ on specimens tempered at different temperatures. The surface morphology of the abraded surface was observed using SEM after ultrasonic cleaning of worn out specimens. 


\section{Results and Discussion}

\subsection{Hardness and Microstructures}

Figure 1 shows the effect of austenizing temperature on the hardening and tempering behavior of En24 steel. It can be clearly seen that hardness dropped with the increase in austenizing temperature from $1123 \mathrm{~K}$ to $1273 \mathrm{~K}$ during hardening. The drop in hardness with increase in austenizing temperature is related to the formation of retained austenite, coarsening of the martensite laths and reduction in the dislocation density. ${ }^{3)}$ The martensitic start $\left(\mathrm{M}_{\mathrm{s}}\right)$ temperature is related to the chemical composition and austenizing temperature during hardening. The $\mathrm{M}_{\mathrm{s}}$ temperature for En24 steel used in the present study was determined by using the relationship given by Andrews: 25$)$

$$
\begin{aligned}
\mathrm{M}_{\mathrm{s}}(\mathrm{K}) & =539-423(\% \mathrm{C})-30.4(\% \mathrm{Mn})-12.1(\% \mathrm{Cr}) \\
& -17.7(\% \mathrm{Ni})-7.5(\% \mathrm{Mo})+273 \ldots \ldots \ldots \ldots \ldots \ldots . . .
\end{aligned}
$$

The increase in alloying content reduces the $\mathrm{M}_{\mathrm{s}}$ temperature and consequently $\mathrm{M}_{\mathrm{f}}$ temperature making austenite retention more pronounced. Another factor affecting the $M_{s}$ and $\mathrm{M}_{\mathrm{f}}$ temperatures is the austenizing temperature. It determines the partitioning of the carbon and alloying elements between the austenite and the carbide phases. The increased austenizing temperature leads to increased dissolution of carbides, higher dissolved alloying elements and grain coarsening. The carbon and carbide forming elements in solid solution depresses the $\mathrm{M}_{\mathrm{s}}$ temperature and consequently the $\mathrm{M}_{\mathrm{f}}$ temperature, increasing the tendency of retention of austenite after quenching. ${ }^{3)}$ Equation (4) predicts the $M_{s}$ temperature of the present steel to be $\sim 581 \mathrm{~K}$. This temperature is well above the ambient and hence the martensitic transformation is likely to proceed to completion. Since the $\mathrm{M}_{\mathrm{s}}$ temperature is well above the ambient temperature and dissolution temperatures of carbides are usually in excess of $\sim 1273 \mathrm{~K}$, the retained austenite (which is expected to be less than $1-2 \%$ in the present case) will get converted to martensite during tempering at $823 \mathrm{~K}$ resulting in an increase in the hardness of the steel with increase in hardening temperature. This phenomenon is observed in Fig. 1, where tempering at $823 \mathrm{~K}$ results in slight increase in hardness with the increase in the austenizing temperature.

The SEM micrographs of annealed sample and samples

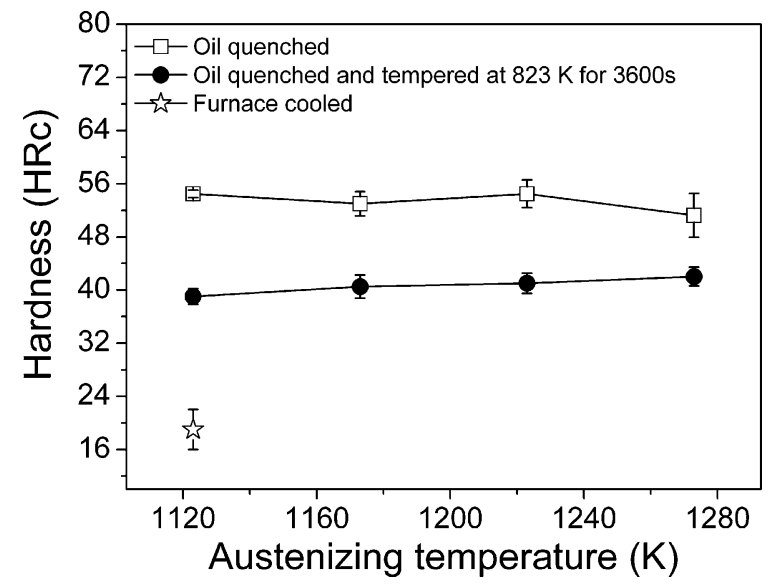

Fig. 1. Variation of hardness (HRc) as a function of austenizing temperature. hardened at $1123,1173,1223$ and $1273 \mathrm{~K}$ are shown in Fig. 2. The annealed sample shows uniform distribution of pearlite colonies throughout the sample. After hardening lath martensite was observed in all the samples. No evidence of retained austenite was visible in the microstructures. The fineness of the martensite laths was, however, dependent on the austenitizing temperature during hardening. Lower austenizing temperatures during hardening resulted in smaller austenite grain sizes and consequently finer lath martensite. This is clearly visible in Figs. 2(b) and 2(e). Deformation by dislocations and twinning are the two alternative mechanisms of lattice invariant deformation. It has been reported ${ }^{3)}$ that low carbon martensite $(<0.5 \% \mathrm{C})$ exhibit only dislocations. The martensite laths or plates are heavily dislocated to an extent that individual dislocations are very difficult to observe in thin foil electron micrographs - making it very difficult to evaluate dislocation density in martensitic steels. Figure 3 shows the SEM micrographs of sample hardened at 1123,1173 and $1273 \mathrm{~K}$ followed by tempering at $823 \mathrm{~K}$ for $3600 \mathrm{~s}$. Martensite in the as-quenched condition is highly supersaturated solid solution of carbon in iron, which during tempering rejects carbon in the form of finely divided carbide phases. This is evident in Fig. 3, which shows a fine dispersion of carbides in the matrix. The size of the carbides increased with the increase in austenizing temperature. The tempered martensite structure after austenizing at $1273 \mathrm{~K}$ consisted of spherical carbides as shown in Fig. 3(c).

\subsection{X-ray Diffraction Analysis}

In the present study, an attempt is made to study the hardening and tempering behavior of En24 steel through X-ray peak profile analysis. It is well known that diffraction peak

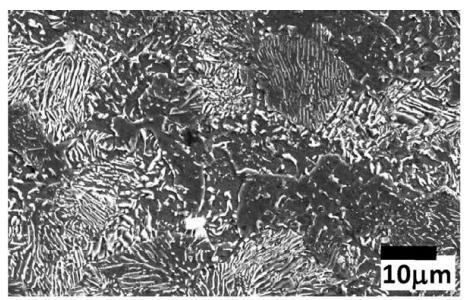

(a)

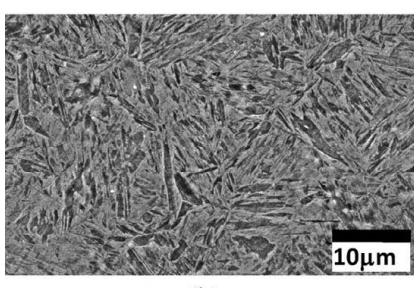

(b)

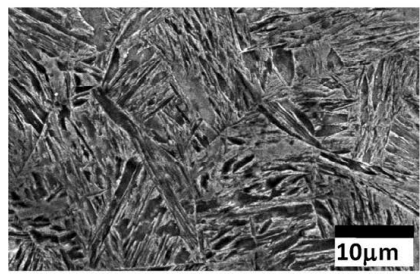

(d)

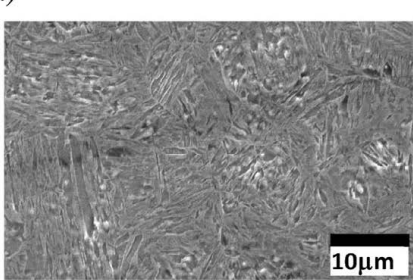

(c)

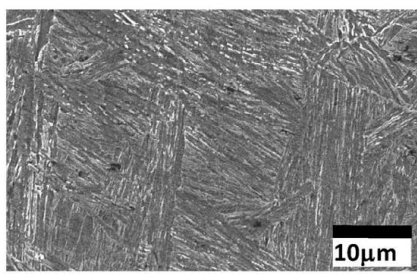

(e)
Fig. 2. Secondary electron scanning electron microscope (SEM) image of En24 steel after (a) annealing at $1123 \mathrm{~K}$ and after austenizing at (b) $1123 \mathrm{~K}$ (c) $1173 \mathrm{~K}$ (d) $1223 \mathrm{~K}$ and (e) $1273 \mathrm{~K}$ followed by oil quenching. 


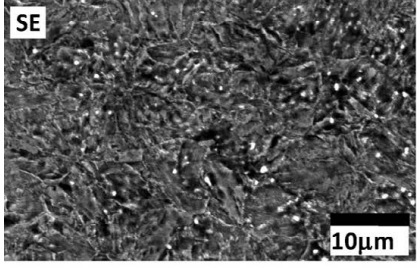

(a)

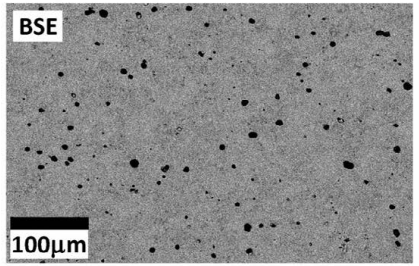

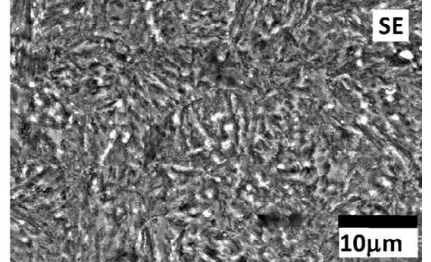

(b)

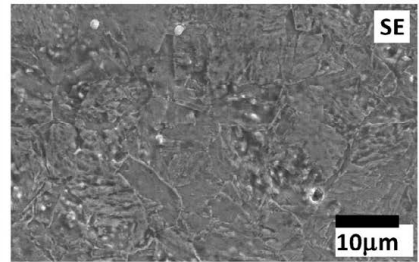

(c)
Fig. 3. SEM images of tempered En 24 steel after austenizing at (a) $1123 \mathrm{~K}$ (b) $1173 \mathrm{~K}$ and (c) $1273 \mathrm{~K}$. All the samples were tempered at $823 \mathrm{~K}$ for $3600 \mathrm{~s}$ followed by air cooling to room temperature. In (c) back scattered electron image is also shown to indicate the distribution of carbides. $\mathrm{SE}=$ Secondary electron and BSE $=$ Backscattered electron.

profiles contain information regarding imperfections in crystalline phases. ${ }^{26)}$ The broadening of XRD peak profiles is primarily caused by (i) size broadening (influence of small crystallite size) and (ii) strain broadening (micro-strain). Strain broadening is usually related to the dislocations causing extended displacement fields in the crystal. ${ }^{20,21)}$ Figures 4(a) and 4(b) show the (110) Bragg peak for samples hardened and tempered after austenizing at 1123 and $1273 \mathrm{~K}$ respectively. Figure 4 brings out the effect of austenizing and tempering - the peak became narrower and more intense with increasing in the austenizing temperature. Also the broadening decreased after tempering as compared to the asquenched (hardened) condition. It needs to be noted that the peaks were corrected for $\mathrm{K}_{\alpha 2}$ contribution using the Rachinger method, ${ }^{27)}$ but were not corrected for instrumental broadening. The microstructures (Figs. 2 and 3) revealed the presence of martensite after hardening and carbides along with martensite after tempering. The crystal structure of martensite is known to deviate slightly from bcc i.e. its tetragonal with $\mathrm{c} / \mathrm{a}=1+0.045 \mathrm{wt} \% \mathrm{C}$. $^{3)}$ However, in the present case, all the XRD peaks were symmetrical (see Fig. 4) and the XRD line patterns could be interpreted on the basis of crystal structure of bcc iron. ${ }^{28)}$ The peak broadening (full width at half maximum - FWHM) of maximum intensity (110) Bragg peak for hardened and tempered En24 steel as a function of austenizing temperature is shown in Fig. 5. It can be observed from Fig. 5 that at low austenizing temperatures, the martensitic microstructure state is broader (qualitatively higher dislocation density) than at higher austenizing temperatures (qualitatively lower dislocation density). Tempering results in increase in the peak broadening with increase in the austenizing temperature. This trend is consistent with the hardness results (Fig. 1); tempering of the already existing martensite and transformation of retained austenite to martensite leading to slight increase in hardness and peak broadening. However, the tempered martensite state has a lower dislocation density (qualitatively) as compared to the corresponding un-tempered martensitic state. ${ }^{3)}$

In order to substantiate the X-ray results further, $\mathrm{WH}^{19)}$

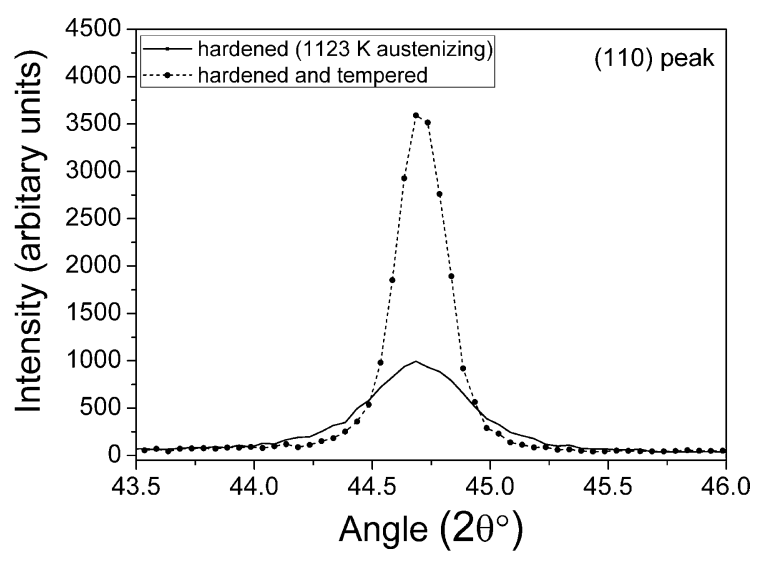

(a)

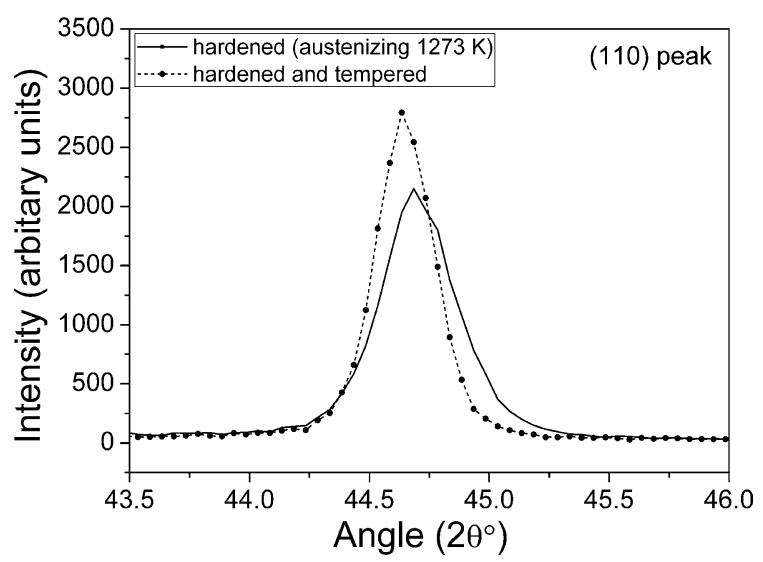

(b)

Fig. 4. (110) X-ray diffraction peak for samples (a) hardened and tempered $(823 \mathrm{~K}-3600 \mathrm{~s})$ after austenizing at $1123 \mathrm{~K}$ (b) hardened and tempered $(823 \mathrm{~K}-3600 \mathrm{~s})$ after austenizing at $1273 \mathrm{~K}$.

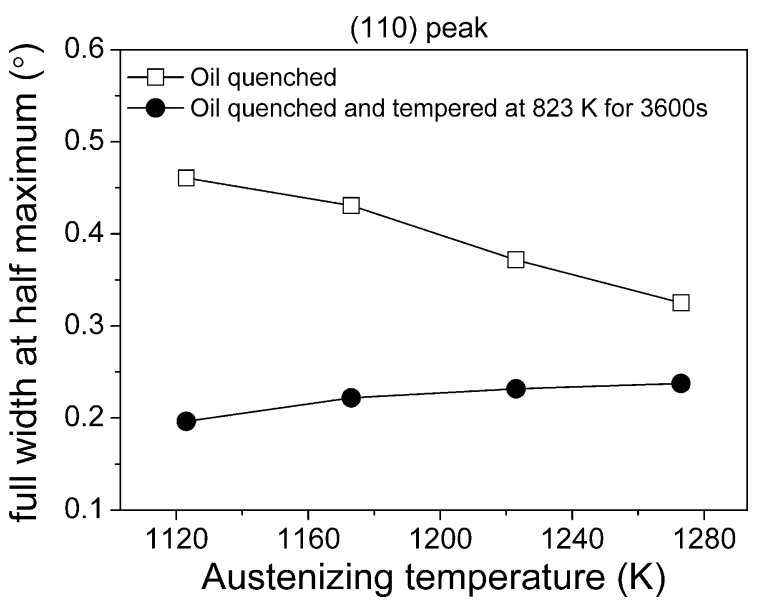

Fig. 5. Full width at half maximum $\left(^{\circ}\right)$ of 110 X-ray peak for (a) as-quenched (hardened) and (b) hardened and tempered samples of En24 steel as a function of austenizing temperature.

and modified $\mathrm{WH}^{20,21)}$ method was used. Figs. 6 and 7 show the WH and $\mathrm{MWH}$ plot for the as-quenched and quenched $\&$ tempered sample for two opposite extremes viz. 1123 and $1273 \mathrm{~K}$ austenizing temperature. It can be observed from Fig. 6(a) that lower austenizing temperature results in pronounced broadening during hardening, while higher temperature austenizing during hardening leads to lower broaden- 


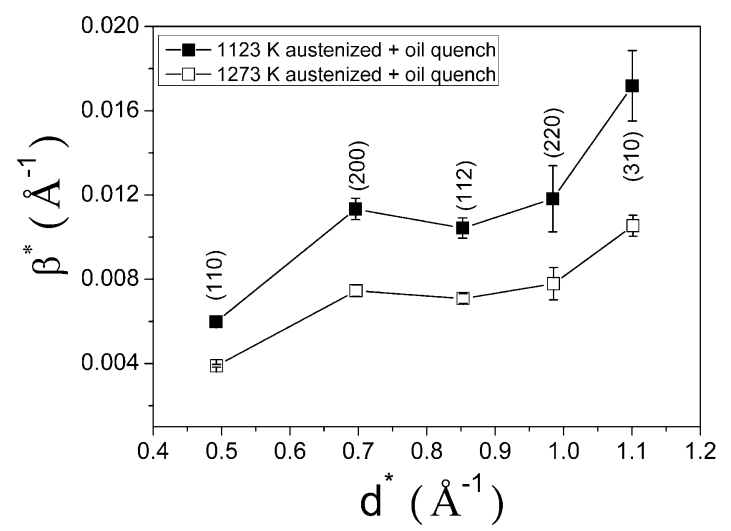

(a)

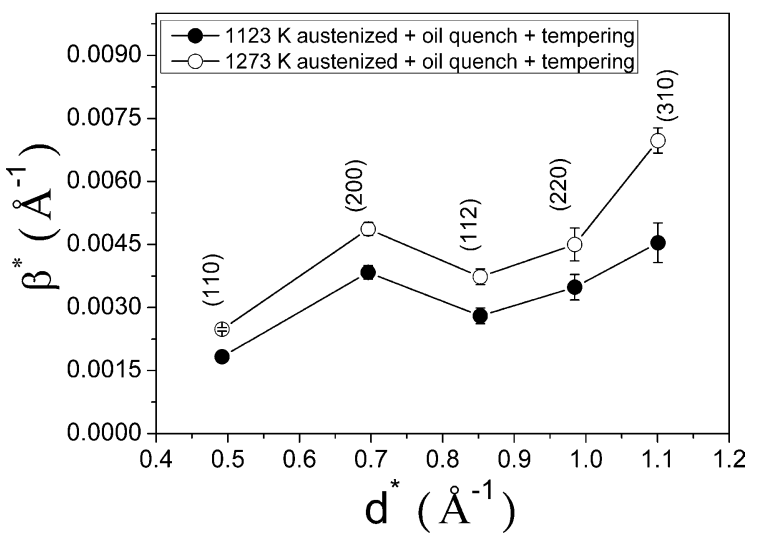

(b)

Fig. 6. Williamson-Hall (WH) plots for (a) as-quenched (hardened) and (b) quenched and tempered $(823 \mathrm{~K}-3600 \mathrm{~s})$ En24 steel samples. Plots are not monotonous indicating anisotropy in peak widths.

ing. Tempering results in decrease of X-ray peak broadening (Fig. 6(b)). It needs to be noted that the peaks in both WH and MWH plots are corrected for instrumental broadening and hence these plots represents the sample feature only. It can be clearly seen that line broadening in WH plots is not a monotonous function of the diffraction angle indicating anisotropy. The (200) and (310) peak in WH plots are much broader as compared to other peaks for all the conditions. These anisotropies can be explained from dislocation induced line broadening and corresponding orientation contrast factors (dislocation model of strain anisotropy) for the most common slip systems in bcc structure. ${ }^{29)}$ These anisotropies can also be caused by tetragonal distortion of the lattice, but this does not affect our results, since no indication of X-ray peak splitting and profile asymmetry was found. In MWH plot, the $\mathrm{X}$-axis is $\mathrm{d}^{*} \mathrm{C}^{1 / 2}$ as compared to $\mathrm{d}^{*}$ in $\mathrm{WH}$ plots. After incorporating the dislocation model of strain anisotropy, the plots are linear for all the conditions. The intercept of linear fit to MWH plots, representing the particle size contributing to X-ray peak broadening (according to Eq. (2)) is of the order of $0.002-0.004 \AA^{-1}$ for the asquenched samples and $0.0015-0.0030 \AA^{-1}$ for tempered samples. In the present analysis, as the particle size term does not directly affect the dislocation density, it is possible to ignore it. The dislocation density was then calculated from WH plot for all the conditions using Eq. (3) after ignoring the (200) and (310) Bragg peak (shown in Fig. 8). The most significant and striking feature of X-ray diffrac-

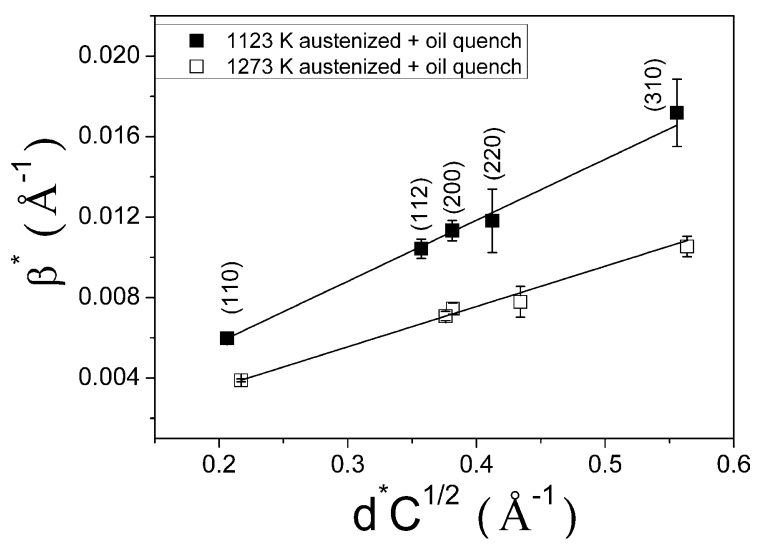

(a)

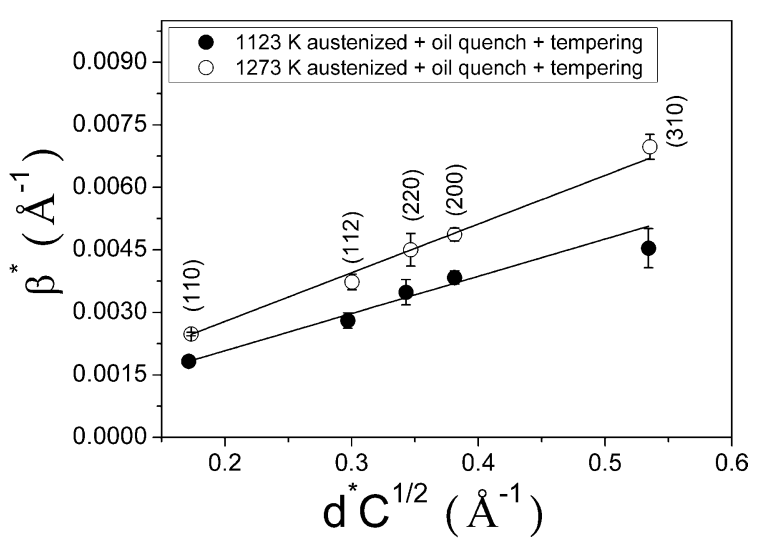

(b)

Fig. 7. Modified WH plots for (a) as-quenched (hardened) and (b) quenched and tempered (823 K for $3600 \mathrm{~s}$ ) En24 steel samples. Plots are monotonous indicating anisotropy in peak widths has been suppressed.

tion results (Figs. 6, 7 and 8) is that the trends for both hardening and tempering are consistent with the hardness results (Fig. 1). In the present study, the results of dislocation density (Fig. 8) were analyzed based on the formulation of Williamson and Smallman ${ }^{24)}$ and using the WH plots. The modified Warren-Averbach analysis ${ }^{30)}$ could not be applied in the present case, since the experimental data was not accurate enough to do the correct Fourier analysis. However, such data on the effect of austenizing temperature on the hardening and tempering behavior of En24 steel is literally non-existent. Therefore, even though the dislocation density results are qualitative, they are compared in the present investigation. Low temperature austenizing (1123 and $1173 \mathrm{~K}$ ) resulted in lowering of the dislocation density by a factor greater than ten after tempering. At these austenizing temperatures, the effect of transformation of retained austenite during tempering was also small. Several past studies have revealed that tempering results in decrease of dislocation density by almost a factor of ten. ${ }^{6}$ High temperature austenizing (1223 and $1273 \mathrm{~K}$ ) resulted in lowering of dislocation density after tempering by factor less than five. The WH method usually gives dislocation densities higher than other X-ray methods (i.e. modified WarrenAverbach) and transmission electron microscopy (TEM) methods. ${ }^{5)}$ 


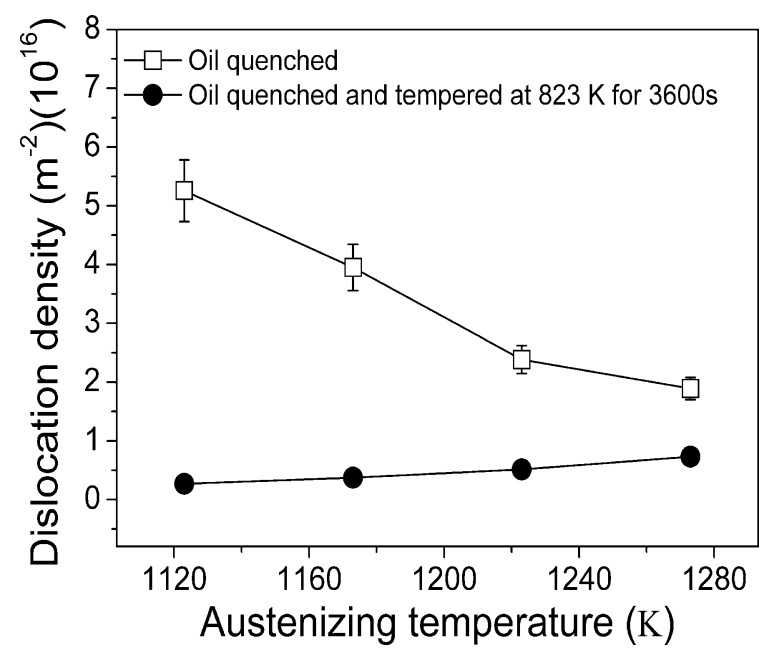

Fig. 8. Dislocation density obtained by using WH plot as a function of austenizing temperature.

\subsection{Abrasive Wear Behavior}

The volume loss $\left(\mathrm{mm}^{3}\right)$ of the annealed En24 steel samples exhibited linear relationship with load as shown in Fig. 9. With the increase in load from $1 \mathrm{~kg}$ to $4 \mathrm{~kg}$ at a velocity of $1.885 \mathrm{~m} / \mathrm{s}$, the abrasive wear volume loss increased from $4.72 \mathrm{~mm}^{3}$ to $28.188 \mathrm{~mm}^{3}$. The increase in load by 4 times resulted in an increase in volume loss by $\sim 6$ times, which can be attributed to increased depth of cut by the abrasive particles on the specimen surface with increased load. ${ }^{16)}$ Since, the volume loss versus load shows a linear relationship, a load of $3 \mathrm{~kg}$ was used for all other samples to study the abrasive wear behavior. The abrasive wear resistance of the heat treated samples was calculated by considering the annealed sample as the reference. Figure 10 shows the volume loss $\left(\mathrm{mm}^{3}\right)$ and hardness (HRc) as a function of tempering temperature for samples hardened at $1123 \mathrm{~K}$. When compared with the annealed sample, the abrasive wear resistance of the samples tempered at 473, 583 and $683 \mathrm{~K}$ increased by a factor of more than 2 . This indicated that tempering results in increase in the abrasive wear resistance of En24 steel for low temperature tempering (i.e. up to $683 \mathrm{~K})$. The high temperature tempering $(823 \mathrm{~K})$ resulted in drop of abrasive wear resistance, which was only 1.2 times as compared to the annealed sample. The increase in abrasive wear volume loss with increase in tempering temperature can be attributed to morphology of the martensitic microstructures, which became coarser with increase in tempering temperature. Similar observations were reported by earlier investigators. ${ }^{14-17)}$ In the present investigation, although the abrasive wear increased with increasing hardness, it was not proportional to the hardness. It needs to be noted that in the present investigation, all the samples were tempered for $3600 \mathrm{~s}$ only. Tempering time can also have a significant effect on the wear resistance of materials, primarily through modifications in the microstructure and consequently hardness. ${ }^{31)}$

The SEM micrographs of worn out specimens of En24 steel hardened at $1123 \mathrm{~K}$ and tempered at 473 and $823 \mathrm{~K}$ are shown in Figs. 11(a) and 11(b) respectively. Figure 11(a) shows long multi-directional grooves, which formed as the abrasive particles plough across the surface and eventually removing or pushing material into ridges along sides of the

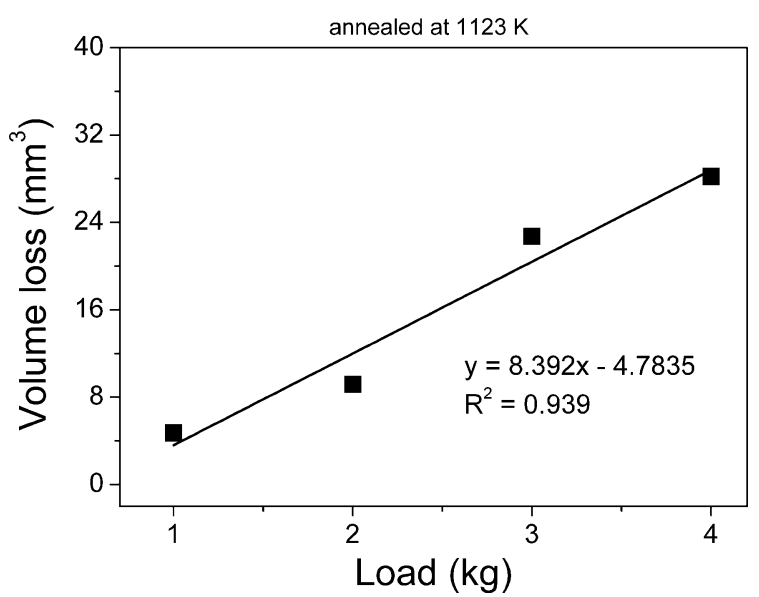

Fig. 9. Volume loss $\left(\mathrm{mm}^{3}\right)$ as a function of load for annealed samples of En24 steel.

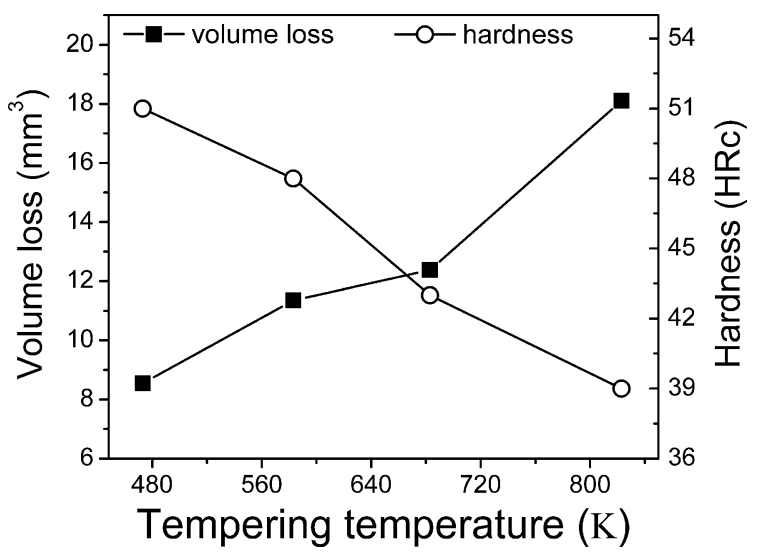

Fig. 10. Volume loss $\left(\mathrm{mm}^{3}\right)$ and hardness (HRc) as a function of tempering temperature for samples hardened at $1123 \mathrm{~K}$.
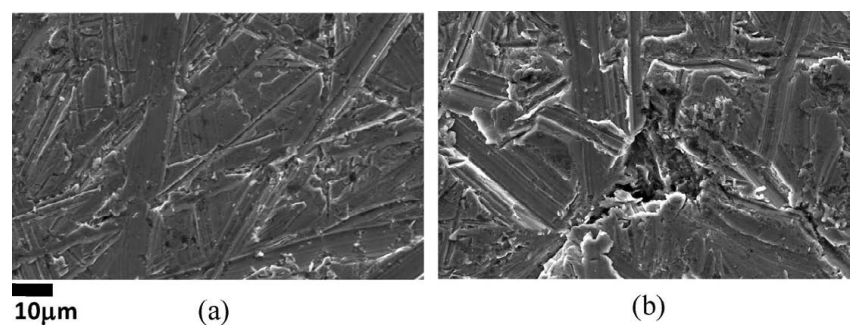

(b)

Fig. 11. Secondary electron SEM images of samples hardened at $1123 \mathrm{~K}$ and tempered at (a) $473 \mathrm{~K}$ and (b) $823 \mathrm{~K}$ for $3600 \mathrm{~s}$. Load used during the wear test was $3 \mathrm{~kg}$. The micron bar applies to both the images.

grooves and scratches on the surface formed by silicon carbide abrasive particle. ${ }^{16,17,31)}$ The SiC particles being harder than the surface were able to cause plastic indentation of the surface. The material removed by ploughing and cutting is visible on the surface at bottom corner and top right of Fig. 11(a). The width and the depth of the groove is relatively less as compared to those observed in Fig 11(b), which shows severely abraded surface of specimen tempered at $823 \mathrm{~K}$. It can also be seen that the size of wear debris particles in Fig. 11(a) are considerably finer, when compared to Fig. 11(b) as can be seen at bottom centre and centre left of the micrograph in Fig. 11(b). This is also indicative of rate of material removal and hence abrasive wear volume loss 
during abrasion, which was observed to be more than two times in the specimens tempered at $823 \mathrm{~K}$ as compared to specimen tempered at $473 \mathrm{~K}$.

\section{Conclusions}

In the present study, the microstructures of En24 steel after hardening and tempering were analyzed using a combination of Scanning Electron Microscopy (SEM) and X-ray diffraction (XRD). The effect of microstructures and hardness on the abrasive wear behavior was also evaluated. The dislocation density was also qualitatively evaluated using the micro-strain measurements using Williamson-Hall (WH) plot obtained from the XRD data. The hardness decreased with the increase in austenizing temperature during hardening, while it increased only slightly with the increase in austenizing temperature during tempering at constant temperature. This slight increase was due to the transformation of retained austenite to martensite during tempering. The hardness results were well supplemented by XRD results (WH \& modified WH plots and qualitatively by dislocation density). The martensitic laths became coarser for higher austenizing temperatures (1223 and $1273 \mathrm{~K}$ ). The abrasive wear resistance although increased with increase in hardness, it was not proportional to the hardness. The finer morphology of the martensite and carbides was responsible for higher abrasive wear resistance at lowest tempering temperature. The mechanisms of material removal during the abrasive wear in En24 steel was found to be cutting and ploughing.

\section{Acknowledgements}

The authors would like to thank Director, VNIT, Nagpur for providing the necessary facilities for carrying out this investigation and for his constant encouragement to publish this work. The authors would also like to thank Prof. P. Scardi and Prof. M. Leoni, University of Trento, Italy for giving access to 'Marqx' program. Thanks are also due to Mr. S.
L. Gadge and Devender K for their assistance during experimentation.

\section{REFERENCES}

1) W. S. Lee and T. T. Su: J. Mater. Proc. Technol., 87 (1999), 198.

2) K. J. Irvine: J. Iron Steel Inst., 12 (1962), 620.

3) R. W. K. Honeycombe and H. K. D. H. Bhadeshia: SteelsMicrostructure and Properties, Butterworth-Heinemann, Oxford, (1995).

4) T. Maki and C. M. Wayman: Metall. Trans. A, 7A (1976), 1511.

5) S. Takebayashi, T. Kunieda, N. Yoshinaga, K. Ushioda and S. Ogata: ISIJ Int., 50 (2010), 875.

6) J. Pešička, R. Kužel, A. Dronhofer and G. Eggeler: Acta Mater., 51 (2003), 4847.

7) S. Morito, J. Nishikawa and T. Maki: ISIJ Int., 43 (2003), 1475.

8) M. Kehoe and P. M. Kelly: Scr. Metall., 4 (1970), 473.

9) L.-Å. Noström: Scand. J. Metall., 5 (1976), 159.

10) K. Holmberg and A. Mathews: Coatings, Tribology, Property, Techniques and Applications in Surface Engineering, Elsevier, The Netherlands, (1994).

11) F. Katsuki, K. Watari, H. Tahira and M. Umino: Wear, 264 (2008), 331.

12) M. H. Shaeri, H. Saghafian and S. G. Shabestari: Mater. Design, 34 (2012), 192.

13) A. Sundström, J. Rendon and M. Olsson: Wear, 250 (2001), 7441.

14) K. Luo and B. Bai: Mater. Design, 31 (2010), 2510.

15) E. Atik, U. Yunker and C. Meric: Tribo. Int., 36 (2003), 155.

16) S. G. Sapate, A. D. Chopde, P. M. Nimbalkar and D. K. Chandrakar: Mater. Design, 29 (2008), 613.

17) S. G. Sapate, C. Gurijala, A. Rathod and A. Singh: Int. Conf. on Adv. Mech. Eng., IDES-CPS, New York, (2011), 98.

18) Y. H. Dong and P. Scardi: J. Appl. Cryst., 33 (2000), 184.

19) G. K. Williamson and W. H. Hall: Acta Metall., 1 (1953), 22.

20) T. Ungàr and A. Borbèly: Appl. Phys. Lett., 69 (1996), 3173.

21) T. Ungàr, S. Ott, P. G. Sanders, A. Borbèly and J. R. Weertman: Acta Mater., 46 (1998), 3693.

22) T. Ungàr and G. Tichy: Phys. Solidi. A, 171 (1999), 425.

23) A. Borbèly, I. Dragomir, G. Ribàrik and T. Ungàr: J. Appl. Cryst., 36 (2003), 160.

24) G. K. Williamson and R. E. Smallman: Philos. Mag., 1 (1956), 34.

25) K. W. Andrews: J. Iron Steel Inst., 203 (1965), 271.

26) B. D. Cullity: Elements of X-ray Diffraction, Addison-Wesley, Reading, Massachusettes, USA, (1958).

27) W. A. Rachinger: J. Sci. Instrum., 25 (1948), 254

28) PDF-2, Powder Diffraction Pattern Database, ICCD, Record Number 04-0836.

29) T. Ungàr, I. Dragomir, À. Rèvèsz and A. Borbèly: J. Appl. Cryst., 32 (1999), 992.

30) T. Ungàr, J. Gubicza, G. Ribàrik and A. Borbèly: J. Appl. Cryst., 34 (1999), 298.

31) Y. Sahin, M. Erdogan and M. Cerah: Wear, 265 (2008), 196. 